\title{
Living with COVID 19: Balancing costs against benefits in the face of the virus
}

\author{
David Miles ${ }^{1}$, Mike Stedman ${ }^{2}$, and Adrian Heald ${ }^{3}$ \\ ${ }^{1}$ Imperial College London \\ ${ }^{2}$ Res Consortium \\ ${ }^{3}$ Salford Royal Hospitals NHS Trust
}

June 17, 2020

\begin{abstract}
The COVID-19 pandemic has transformed lives across the world. In the UK there has been a public health driven policy of population 'lockdown' that had enormous personal and economic impact. We compare UK response/outcomes including excess deaths with European countries with similar levels of income/healthcare resources. We calibrate estimates of the economic costs as different \%loss in GDP against possible benefits of avoiding life years lost, for different scenarios where local COVID-19 mortality/comorbidity rates were used to calculate the loss in life expectancy. We apply quality-adjusted life years (QALY) value of $£ 30,000$ (maximum under NICE guidelines). The implications for future lockdown easing policy in the UK are also evaluated. The spread of cases across European countries was extremely rapid. There was significant variation both in severity and timing of both implementation and subsequent reductions in social restrictions. There was less variation in the trajectory of mortality rates and excess deaths, which have fallen across all countries during May/June 2020. The average age at death and life expectancy loss for non-COVID-19 was 79.1 and 11.4years respectively while COVID-19 were 80.4 and 10.1years; including for life-shortening comorbidities and quality of life reduced this to 5QALY for each COVID-19 death. The lowest estimate for lockdown costs incurred was $50 \%$ higher than highest benefits from avoiding the worst mortality case scenario at full life expectancy tariff and in more realistic estimation they were over 50 times higher. Application to potential future scenarios showed in the best case a QALY value of $£ 220 \mathrm{k}$ (7xNICE guideline) and in the worst-case $£ 3.7 \mathrm{~m}$ (125xNICE guideline) was needed to justify the continuation of the lockdown. The evidence suggests that the costs of continuing severe restrictions in the UK are so great relative to likely benefits in numbers of lives saved so that a substantial easing in restrictions is now warranted.
\end{abstract}

\section{Introduction}

In early March 2020, it seemed that the COVID-19 virus in the United Kingdom was spreading exponentially with no clear sign of imminent slowing; the fatality rate was unknown and the ability of the National Health Service (NHS) to deal with rapidly rising numbers of seriously ill people was unclear. Estimates made at that time put the likely level of UK deaths if there was no change in behaviour at 500,000 (1). Based on that, and other, assessments the UK government followed the example of several other European countries in introducing severe restrictions on individual movement. The key message was to stay at home; this was a lockdown. That served both to slow the spread of the virus and to signal in a very clear way that people needed to quickly change behaviours, but it also generated great costs. The extent to which the lockdown contributed to a subsequent slowing in the rate of new infections and deaths is not clear. This paper summarises the evidence on this as part of a wider assessment of costs and benefits of severe restrictions - "lockdowns". We do so to inform the decisions on how restrictions in the UK should be lifted.

While it is clear that the cost of the lockdown has been large, just how great it is will not be known for many years. This cost - as well as the benefits of lockdowns - should be measured in terms of human welfare 
in the form of length and quality of lives. Such measurement is profoundly difficult. Yet measurement of the costs of restrictions needs to be weighed against the benefits of different levels of restrictions to assess what is the best policy now. The cost of severe restrictions plausibly rises more than in proportion to the length of a lockdown. Two months of missed treatments for cancer, of company closures, of postponed screening for serious health conditions, of lessons missed at schools and universities, of many people living in very stressful situations is likely more than twice as bad as one month. In contrast, the benefits of maintaining a severe set of restrictions - the lockdown - may be diminishing as described in Bongaerts et al (2020) (2). Decisions on how to ease restrictions are therefore of immediate significance.

In this article, we aim to calibrate what the costs and benefits of severe restrictions might be and what that implies about the policy that should now be followed. We look at evidence from many countries, focusing particularly on European countries with similar levels of income and healthcare resources. We then draw out what this implies for policy in the UK.

\section{Methods/Structure}

Section 1 summarises evidence on recorded cases of the virus, deaths, and excess deaths - all in the context of restrictions adopted. Section 2 turns to issues of interpretation focusing on how much of the slowdown in the spread of the virus, and of deaths attributed to it, may have been due to lockdowns and how much to the curve turning down independently of severe restrictions. Section 3 summarises evidence from countries with different policies and draws some conclusions on the scale of benefits of the lockdown. Section 4 focuses on the costs of restrictive policies to slow the spread of the infections; section 5 brings costs and benefits together and section 6 considers policy options for coming out of lockdown. Conclusions are drawn in a final section.

\section{Section 1: Recorded cases, deaths and excess deaths}

Figure 1 shows the number of new positive cases tested for in several European countries between early 2020 and June. Figure 2 shows cumulative deaths where there is evidence that the deceased had the COVID-19 infection. Figure 3 shows a measure of excess deaths - that is total deaths above the average of such deaths over the comparable months in previous years. Figure 4 shows a measure of the stringency of government restrictions introduced in European countries to counter the spread of the virus.

Several measurement issues make it difficult to draw conclusions from these data with high confidence. The number of tests undertaken (relative to population) varies within countries over time and also between countries and this will affect the numbers who tested positive for the virus and the prevalence of untested cases. While data on the numbers of deaths is reliable, ascribing death to the virus is not - even if one could accurately measure the numbers who have died with the virus the prevalence of co-morbidities means that drawing conclusions about the scale of deaths caused by the virus is problematic. Focusing on "excess deaths" is a different way of assessing the impact of the virus but since some deaths will be a result of restrictions, rather than infections, it is also an imperfect measure.

Despite measurement issues, certain conclusions from the data in Figures 1-4 seem robust.

1. The spread of the infection after the first few recorded cases within European countries was extremely rapid and consistent with initial reproduction numbers far in excess of 1 and quite likely close to 3.

2. In late February or early March 2020, many European countries brought in severe restrictions on movement meaning that the majority of populations stayed home and numbers able to work fell dramatically (as shown in Figure 4). Such restrictions came in earlier in countries where the numbers recorded with the infection had risen sharply earliest - most notably Italy. There were also places where restrictions were much less severe than in most countries - most notably in Sweden.

3. New measured cases of the infection and of deaths ascribed to the virus were significantly lower within a few weeks of restrictions being introduced. There is some evidence of a flattening in new cases ahead of severe restrictions being introduced. 
4. The slowing in new infections and in deaths has been marked in all countries in recent weeks, though the severity of restrictions and the timing of those restrictions differ.

\section{Section 2: How much was due to lockdowns?}

What is not clear from data on measured deaths of people who are recorded as having the virus, on tested new cases of the infection and on excess deaths is the extent to which they have fallen because of (in many cases severe) restrictions on the population. There are at least three reasons why new infections and deaths could have fallen, perhaps sharply, even with much more limited government restrictions short of a lockdown: i. individuals would have altered their behaviour (washing hands more frequently, avoiding crowded spaces etc) with no legal restrictions on the ability to leave the home and with much more limited disruption to life; ii. a significant degree of immunity may have built up by the time severe restrictions were introduced because the infection may have spread quite widely and largely unnoticed with the asymptomatic a large fraction of the infected. iii. a substantial proportion of the population may have been effectively immune from the virus when lockdowns started not just because of recovery from past infections that conferred a degree of immunity but also because some proportion of the population was never susceptible. All three factors may have played a role, and all would mean that deaths and new infections would have slowed in the absence of severe government restrictions.

These three factors are not mutually exclusive and there is some (less than conclusive and often disputed) evidence that each of them may have played a role.

An Oxford University research team used death data to estimate the proportion of the population who might have built up some form of immunity before the UK lockdown was introduced in mid-March 2020. They put that fraction at around 60\% (Lourenço et al (2020)) (3). Stedman et al (2020) (4) used data on differences in the spread of the infection across English regions to assess how many might have been infected and put that fraction at similarly high levels. Dimdore-Miles and Miles (2020) (5) fitted a SIR (Susceptible-InfectedRecovered) model to data on new cases of infections across several countries and estimated that the numbers who might have been infected with no (or few) symptoms were likely to be at least 10 times (and possibly as much as 200 times) as large as those who had symptoms and were more likely to have been tested up to late April 2020.

Wieland (2020) (6) modelled the spread of the infection across Germany and concluded that infections were past their peak and starting to decline ahead of the introduction of government restrictions there. The results were summarised thus: "In a large majority of German counties, the epidemic curve has flattened before the social ban was established (March 23). In a minority of counties, the peak was already exceeded before school closures."

Professors Karl Friston (of University College London) (7) and Michael Levitt (of Stanford University) (8) experts in the application of statistical models to biological phenomena - have independently concluded that the numbers of people susceptible to the COVID-19 virus were substantial before lockdowns were introduced and that the virus may have been burning itself out.

Despite these pieces of evidence, direct measures of how many people in the wider population have been infected by COVID-19, and the extent to which immunity from the virus has been built up by that route, are not high. Most estimates based on limited testing of a random sample of the population for antibodies put the level of those who have had the infection in European countries where the virus has spread most rapidly at $5-10 \%$, though in some areas within countries it is still high enough to have had a significant impact on R.

It is nonetheless clear that the asymptomatic make up a high proportion of total infections - one of the reasons that some immunity has been built up without hospitals being swamped. It is possible that serology testing for past COVID-19 infection based on the presence of antibodies are not picking up cases where the infected had very few symptoms and not identifying others who are nonetheless not susceptible to the virus.

\section{Section 3 The evidence from countries with different policies: Sweden vs UK}


In contrast to many other European countries, the Swedish strategy has been one of adopting much less restrictive measures that is far short of a lockdown (see Figure 4). In terms of the health impacts, there is mixed evidence over how different they are compared to those in countries that adopted lockdown policies. The study by Born et al (2020) (9) estimates how the infection might have spread if Sweden had imposed a lockdown like many other European countries. They find essentially no difference in the likely path of infections. Krueger, Uhlig and Xie (2020) (10) assess how economies might have evolved during the pandemic with few government restrictions. They conclude:

"One may view our results as the "Swedish" outcome: Sweden has largely avoided government restrictions on economic activity, allowing people to make their own choices. These private incentives and well-functioning labour-and social-insurance markets, we submit, may solve the COVID-19 spread on their own, mitigating the decline in economic activity."

But the study by Conyon et al (2020), which compares deaths in Sweden with those in Norway and Denmark, finds strong evidence that the looser restrictions in Sweden compared with its close neighbours led to significantly more people dying.

Despite this the UK data show a significantly higher cumulative death rate than Sweden (Figure 2); Financial Times estimates (11), as well as those shown in Figure 3 above, put excess deaths relative to population in the UK at more than twice the Swedish level by early June 2020. On this measure Figure 3 shows that Sweden sits near the middle of the pack for European countries. While cumulative death rates for Sweden remain markedly higher than in its immediate neighbours, they are not very different from European averages. Cases of new infections in Sweden in early June 2020 did, however, increase, unlike in most other European countries where they continued to decline even as lockdowns have begun to be eased.

\section{How effective was the lockdown?}

It is clear that there is contradictory evidence on the effectiveness of the lockdown strategy. In the UK it is hard to be sure of the scale of benefits: they range from very few lives saved to a high of perhaps 450,000 lives saved (that is the difference between the 500,000 or so deaths projected by Ferguson et al (2020) (1) on the basis of no change in behaviour and the 50,000 or so deaths that might have resulted in the UK by early June 2020). Figures for lives saved in the UK at either end of that spectrum (near zero or as high as 450,000) seem implausible.

There are reasons to be sceptical of figures at the high end of that scale which puts the saving of lives from the lockdown at several hundreds of thousands:

- the low cost of effective forms of behavioural change (washing hands, avoiding crowds) adopted by individuals makes it rather unlikely that in the UK there would have seen 500,000 deaths even with no government restrictions; the 500,000 figure from Ferguson et al (2020) (1) was based on an assumption of no change in individual behaviour.

- the evidence of a turn in the curve before lockdowns are likely to have had much effect is disputed but not easily dismissed.

- even if lockdowns stopped such huge numbers of deaths over the period March-June 2020 they have not permanently stopped them happening if wider immunity has not significantly risen so that any substantial easing of restrictions will just bring them back.

- in many countries deaths were concentrated in care homes for the elderly and have been disproportionately among older people so a blanket lockdown ("don't leave home") may have been inefficient - it generated huge costs (see below) and may have yielded limited health benefits, over and above what might have been achieved with measures which focused on groups most at risk.

\section{Section 4: The costs of lockdowns}

Measurement issues for the costs of lockdowns are different from those that make the assessment of the benefits difficult, but they are also significant. While some of the costs are clear and immediate (GDP is lower, the fiscal deficit is higher, unemployment has risen a great deal) even here it is not straightforward to 
judge their true scale of cost because of two issues: a. how permanent will the losses be? b. how great would such problems have been even with no lockdown? Costs which will come further down the road because of disruption to healthcare and education are harder again to measure relative to the more immediate effects on economic production and employment.

A great deal of evidence is already emerging on the (narrow) economic impacts of restrictions. Estimates made by Deb et al (2020) (12) to identify the particular effect of restrictive policies (lockdown) suggest that they reduced economic activity by $15 \%$ in the 30 days after they were adopted. They find that stay-at-home requirements and workplace closures are the costliest in economic terms. Preliminary estimates from the UK Office for National Statistics showed a slightly more than 20\% fall in GDP in April 2020, the first full month after the lockdown. Bonadio et al (2020) (13) put the impact on output and incomes (i.e. GDP) of policies to counter the spread of the infection on GDP averaged across 64 countries even higher, at around 30\%.

Aum et al (2020) (14) estimate that around one-half of all job losses in the UK and US can be attributed to lockdowns. Coibion et al (2020, a) (15) estimate that there were 20 million lost jobs in the US by April $8^{\text {th }}$ triggered overwhelmingly by government restrictions, far more than jobs lost over the entire Great Recession. Furthermore, many of those losing jobs were not actively looking to find new ones. Participation in the labour force declined by 7 percentage points, an unparalleled fall that dwarfs the three percentage point cumulative decline that occurred from 2008 to 2016 after the financial crisis. In a related paper the same authors undertake surveys of behaviour and economic outcomes across US regions with different degrees of restrictions. They conclude:

"We observe a dramatic decline in employment and consumer spending as well as a bleak outlook for the next few years. Our estimates suggest that this economic catastrophe can be largely accounted by lockdowns." (16)

Around 9 million people (one-quarter of the workforce) have been furloughed in the UK and paid largely by the government. The OBR reported in May that UK net government debt rose by 17.4 per cent of GDP on a year earlier to 97.7 per cent in April. Extra debt issuance is likely to be around 10\% of GDP in 2020 and the stock of debt likely to be already close to $100 \%$ of GDP in mid- 2020 and likely to go higher in 2021.

For the UK the Office for Budget Responsibility (OBR) and the Bank of England estimate that GDP is likely to have fallen by between $25 \%$ and $35 \%$ in Q2 2020 and by 10-15\% in 2020 relative to 2019; unemployment may rise to around 10\%. The OBR central estimate, and the illustrative scenario for the Bank of England made in May 2020, is that in 2020 the UK GDP will be around 13-14\% lower than in 2019. The June Organisation for Economic Cooperation and Development forecast is for an $11.5 \%$ decline in UK output in 2020 and for output to remain lower in 2021 than it was in 2019.

The estimates from the Bank of England and the OBR assume that restrictions are eased after June and that effectively the lockdown is then soon over; it seems plausible that their estimates of economic cost are therefore estimates of the impact of the lockdown that has been in place in the UK from March to June and not of a continuation of the lockdown into the second half of 2020 and beyond. The OBR is explicit about this; in describing their forecasts they note: "The table below summarises the results of our threemonth lockdown scenario where economic activity would gradually return to normal over the subsequent three months." The Bank of England in its May economic assessment takes a similar line: "Underlying the illustrative scenario for both the UK and the rest of the world is an assumption that enforced social distancing measures remain in place until early June and that they are then lifted gradually over the following four months, until the end of Q3". In that illustrative scenario GDP in 2020 is $14 \%$ below the 2019 level (Table 1A, Bank of England May Monetary Policy Report) (17). But it is hard to be sure how these assessments would have been different with much less restrictive policies; economic activity would almost certainly have been lower, at least to some extent.

Many elements of the cost of the lockdown in the UK are not reflected at all in current incomes, employment and GDP. Health costs - including mental health - are not yet showing up in a measurable way. They are likely to be large and long-lasting. Referrals for cancer investigations were 70\% down in April 2020 (18); 
there were hardly any follow-up routine appointments for long term conditions in UK Primary Care between mid-March 2020 and the beginning of June 2020; outpatient seen were $64 \%$ down and elective admissions were $75 \%$ down (19); attended appointments in General Practice were down 35\% (19). The impact of the stress of the 'Lockdown' on anyone with a pre-existing mental health condition, let alone the population as a whole, is yet to be determined.

The cost from disrupted education of children and students will be felt over a horizon of many years, even decades.

\section{Section 5 - Bringing costs and benefits together:}

Bringing together costs and benefits is necessary if good policy decision are to be made. There is no simple way to do this that is clearly ethically justifiable, empirically reliable and widely accepted. But to make no assessment is just to make policy in a vacuum. One approach is to focus on quality-adjusted life years (QALYs) that may have been saved as a result of restrictions that have been in place in the UK up to early June and to convert that to a metric that can be compared with estimates of the cost of the restrictions. That is the strategy we follow. We then go on to make estimates of costs and benefits of alternative ways forward with restrictions eased to different extents.

We make use of the guidelines established in the UK by the National Institute for Health and Care Excellence (NICE) for the use of resources in the UK health system (see NICE (2013) (20). These are guidelines applied to resource decisions that have a direct impact on lives saved. It is hard to see how you could run a public health care system without such rules. The guidelines in the UK set out by NICE are that treatments that are expected to increase life expectancy for a patient by one year (in quality of life adjusted years, QALYs) should cost no more than $£ 30,000$. We apply that figure to possible total numbers of QALYs saved by restrictions to estimate their benefit.

To implement this we need to assess how many likely extra years of good life might be enjoyed by the people who would have died but for a lockdown. We assume that the age and health of those who would have died are similar to that of those who have died with the virus.

The Office for National Statistics (ONS) has been publishing each week the number of deaths where COVID19 has been recorded as a possible cause by quinary age and gender. In total up to the week ending 22 May, this was 43,694 in England and Wales. (This total is 21\% below the excess all causes deaths figure of 55,504 up to w/e $24^{\text {th }}$ May (Week 21) calculated by comparing the actual recorded number in 2020 to the average deaths over previous 3 years in the same period).

By applying the average life expectancy (21) to the actual recorded COVID-19 deaths by age and gender a total life expectancy years lost can be calculated. Table 1 shows the calculation. Average life expectancy loss comes out at 10.1 years per COVID-19 death. (The average life expectancy years lost for a non COVID-19 death is higher at 11.4 confirming that the age for COVID mortality is older than normal mortality). The median COVID-19 age at death is around 80 and the average life years lost for the older $50 \%$ is 5 years and the for younger $50 \%$ is 15 years. 


\begin{tabular}{|c|c|c|c|c|c|c|c|c|}
\hline $\begin{array}{l}\text { Up to } 24^{\text {th }} \\
\text { May } 2020\end{array}$ & $\begin{array}{c}\text { Total } \\
\text { Deaths }\end{array}$ & & $\begin{array}{l}\text { COVID-19 } \\
\text { Total Deaths }\end{array}$ & & $\begin{array}{c}\text { Life } \\
\text { Expectancy } \\
\text { (Years) }\end{array}$ & & $\begin{array}{c}\text { Total } \\
\text { Expected } \\
\text { Life }\end{array}$ & \\
\hline Age Group & Male & $\begin{array}{l}\text { Fe- } \\
\text { male }\end{array}$ & Male & $\begin{array}{l}\mathrm{Fe}- \\
\text { male }\end{array}$ & Male & Female & $\begin{array}{c}\text { Non } \\
\text { COVID }\end{array}$ & $\begin{array}{c}\text { COVID- } \\
19\end{array}$ \\
\hline$¡ 1$ & 576 & 446 & 2 & 0 & 79.3 & 82.9 & 82476 & 159 \\
\hline $1-4$ & 89 & 64 & 0 & 1 & 77.1 & 80.7 & 11949 & 81 \\
\hline $5-9$ & 56 & 31 & 0 & 0 & 72.6 & 76.3 & 6432 & 0 \\
\hline $10-14$ & 61 & 54 & 0 & 1 & 67.7 & 71.3 & 7907 & 71 \\
\hline $15-19$ & 203 & 100 & 5 & 4 & 62.7 & 66.3 & 18787 & 579 \\
\hline $20-24$ & 325 & 142 & 13 & 9 & 57.8 & 61.4 & 26214 & 1305 \\
\hline $25-29$ & 465 & 208 & 29 & 16 & 53 & 56.5 & 33950 & 2440 \\
\hline $30-34$ & 654 & 358 & 46 & 29 & 48.2 & 51.6 & 46259 & 3712 \\
\hline $35-39$ & 1003 & 635 & 65 & 49 & 43.4 & 46.7 & 68081 & 5110 \\
\hline $40-44$ & 1406 & 856 & 139 & 81 & 38.7 & 41.9 & 81497 & 8772 \\
\hline $45-49$ & 2326 & 1568 & 256 & 153 & 34.1 & 37.1 & 123136 & 14412 \\
\hline $50-54$ & 3884 & 2469 & 476 & 277 & 29.6 & 32.5 & 172061 & 23085 \\
\hline $55-59$ & 5633 & 3625 & 876 & 417 & 25.2 & 27.9 & 209590 & 33741 \\
\hline $60-64$ & 7640 & 5019 & 1234 & 617 & 21 & 23.6 & 238458 & 40495 \\
\hline $65-69$ & 10575 & 6848 & 1643 & 845 & 17.1 & 19.3 & 268990 & 44464 \\
\hline $70-74$ & 16314 & 11331 & 2665 & 1406 & 13.4 & 15.4 & 335960 & 57429 \\
\hline $75-79$ & 20131 & 15452 & 3640 & 2235 & 10.2 & 11.7 & 322234 & 63145 \\
\hline $80-84$ & 24854 & 22256 & 4782 & 3478 & 7.3 & 8.5 & 306689 & 64625 \\
\hline $85-89$ & 25537 & 28624 & 4650 & 4234 & 5.1 & 5.9 & 249665 & 48572 \\
\hline $90+$ & 22873 & 42080 & 3812 & 5509 & 2.9 & 3.2 & 172665 & 28711 \\
\hline Total & 144605 & 142166 & 24333 & 19361 & & & 2783000 & 440907 \\
\hline Mean Age & 76.9 & 81.5 & 78.7 & 82.5 & & & & \\
\hline Non & & 243077 & Covid-19 & 43694 & & Lost & 11.4 & 10.1 \\
\hline Covid-19 & & & & & & Years/D & & \\
\hline
\end{tabular}

Table 1: Estimating Total possible Life Years Lost to Deaths in Non COVID and COVID-19 in 2020 up to week ending 24th May

The average figure of 10.1 years of life lost does not account for the fact that those who have died with COVID19 have often been in poor health, conditional on their age. In their detailed study of 23,804 hospital deaths in England from COVID-19 from 1st March 2020 to 11th May 2020, Valabhji et al (2020) (22) found that various life-shortening risk factors were significantly more prevalent in those patients who died of COVID19 than in the general population. This included diabetes (33\% vs 5\%), and previous hospital admission for significant cardiovascular comorbidities including coronary heart disease (31\% vs 3.5\%), cerebrovascular disease $(19.8 \%$ vs $1.5 \%)$ and heart failure (17.7\% vs $1 \%)$.

Other comorbidities such as dementia in its various forms, chronic obstructive pulmonary disease (COPD), vitamin D deficiency, and hyperlipidaemia were not collected and compared, but it is plausible that these would also show similar levels of differences. Each of these comorbidities has been shown to significantly increases the risk of early death. The National Diabetes Audit in their mortality study (23) found that the presence of diabetes increases a person standard mortality risk by a factor of 1.6.

It is, therefore, plausible that those patients who died of COVID-19 were, on average, already in relatively poor health for their age and this poor health would give them a life expectancy, on average, significantly below that of the age-equivalent general population. 
These comorbidities and conditions also reduce the person's quality of life, as well as its quantity (24). The impact of poor health through long-term conditions and comorbidities are usually incorporated into modelling through a quality of life utility factor which ranges from 1 (healthy) to 0 (death); this is used to adjust the total life years. Beaudet et al (2014) (25), found that the basic type 2 diabetes without complication had a factor of 0.79 and then other comorbidities would reduce this further including myocardial infarction -0.06 , ischemic heart disease -0.09 , heart failure -0.11 , and stroke -0.16 . An average poor health utility factor of 0.8 could be applied to the population of those who have died with COVID-19.

A substantial downwards adjustment to the 10 years estimate of the residual life expectancy based on the general population would seem appropriate for the group who have died with COVID-19. How great an adjustment is hard to be precise about, but It might plausibly be by one half. In the calculations below we apply either no adjustments for co-morbidities or an adjustment of one-half, using lost average qualityadjusted life years per COVID-19 death of 10 or 5 years.

\section{A cost-benefit analysis of the lockdown:}

The benefit in terms of estimated lives saved

Suppose that a group of people who each had expected quality-adjusted remaining years of life of 5 years, and who might have died with the virus, has been spared that because of government restrictions ("the lockdown"). We will assume that the benefit of the restrictions that prevented such deaths are the value of 5 quality-adjusted years of life multiplied by the number of lives saved. The NICE $£ 30,000$ threshold is an assessment of the (maximum) resource cost that would be justified for the UK health service to make an expected saving of one quality-adjusted year of life. To save 5 QALY would be worth up to $£ 150,000$.

We apply this figure of $£ 150,000$ (or a figure of $£ 300,000$ if we make no adjustment for co-morbidities and take 10 life years lost per death) to estimates of the possible number of lives saved as a result of lockdowns to give an overall benefit number. We compare that aggregate number with an estimate of the lost resources from the lockdown. As noted above there is no single, reliable estimate of lives that have been saved by the UK lockdown and nor is there a widely accepted single figure for the comprehensive overall cost of the lockdown (which should include lost and damaged lives into the future as a result of severe restrictions and not just lost incomes in 2020). So we present a range of estimated costs and benefits based on a wide range of assumptions that we think encompass plausible upper and lower limits on both costs and benefits.

At the high end of estimated lives saved is the difference between the projected deaths from the study of Professors Ferguson's group at Imperial assuming no change in behaviour $(500,000)$ (1) less an estimate of excess UK deaths (approximately 60,000 by June 2020). This 440,000 net lives saved number is likely to be a significant overestimate of likely lives saved. As noted above it does not account for changes in behaviour that would have occurred without the government lockdown; it does not count future higher deaths from side effects of the lockdown (extra cancer deaths for example); it does not allow for the fact that some of those "saved" deaths may just have been postponed because when restrictions are eased. In the absence of a vaccine or of widespread immunity, deaths may pick up again. (If the epidemic is dying out anyway those deaths will not come as the lockdown is eased but in this case, the 440,000 saved lives are also excessive because the lockdown may have come as a decline in infections was happening for other reasons).

At the other end of the spectrum would be estimates of net saved lives that are effectively zero. We set the lowest estimated net set lives well above that and use (rather arbitrarily) a "lowest" estimate of 20,000.

For each life saved we apply a factor of either 5 or 10 quality-adjusted extra years of life, each valued with the NICE guideline figure of $£ 30,000$ (20).

\section{The cost}

On the cost side the lowest resources cost is just to count the GDP that would have been produced in 2020 but for the lockdown established in March and assuming the lockdown to be eased from the end of June. This assumes a rapid bounce back by the end of the year so there is no effect on incomes and output from the 
start of 2021 onwards. That was the scenario envisaged by the Bank of England in their May 2020 assessment of the economic outlook when they put the GDP loss in 2020 at around $14 \%$. The OBR estimate for lost output in 2020, also based on an assumed rapid recovery in the second half of the year, is close to $13 \%$. It seems plausible that a large fraction of these estimates of lost output is due to the lockdown. But even absent a government-mandated lockdown there would have been some reduction in incomes. If the lockdown effect was two thirds of what the OBR and Bank of England suggest is the loss in GDP for 2020 that might imply around a 9\% fall in GDP as a direct result of it. That is around $£ 200$ billion.

That $9 \%$ of GDP cost is likely to be a low-end estimate of overall costs of the UK lockdown from mid-March to early June as it:

- assumes lost output from the first half of 2020 comes back quickly-in fact, the lasting effects of job losses in the UK seem very substantial. Typical estimates are of a lasting wage penalty from unemployment of 8-10\% and an employment penalty of 6-9\% (Arulampalam et al. 2003, Tumino 2015) and the impacts are particularly severe for young people.

- ignores wider health costs of future lives damaged - in fact, recent work by, among others, Carol Propper, professor of economics at Imperial College, and researchers at the Institute for Fiscal Studies (IFS) suggests that the relatively modest increases in unemployment associated with the 2008-09 financial crisis may have resulted in 900,000 more people of working age suffering from chronic health problems. See Propper et al (2020).

- assumes zero costs from disruption to the education of the young -in fact, such costs are likely to be significant. Paul Johnson, Director of the IFS, in an article from late May said: "Younger generations "will pay a heavy price for our response to this virus". So say Anna Vignoles and Simon Burgess, perhaps Britain's foremost authorities on the economics of education. They are right, and we should be worried. They are talking about the effects of school closures on children's education and the effects of the deepest recession in history on the job and earnings prospects of those young people entering the labour market this year. These effects will be damaging, long-lasting and felt much more acutely by those who are already disadvantaged." (The Times, May 26th)

At the high end of the spectrum would be an estimate of 15\% of GDP lost in 2020 and lower output for the next few years on top of that as economic activity does not return to normal for several years with some firms permanently damaged by the lockdown and the large rise in unemployment slow to be reversed, even if restrictions are quickly removed from mid-2020. A shortfall of GDP of 15\% in 2020; 7.5\% in 2021 and $2.5 \%$ in 2022 would be at the more pessimistic end of the spectrum for the impact of the March-June lockdown, though for many economists such a figure seems realistic rather than pessimistic. The cumulative lost output would then be $25 \%$ of GDP.

\section{Cost/Benefit Balance}

It should be stressed that these are scenarios - not forecasts. But we believe they cover high and low ends of a plausible range for both costs and benefits of lockdown. Tables 2 and 3 show the cost-benefit calculations of the lockdown based on such ranges: In each cell, we report three numbers: benefits (+), costs (-) and (in red) the balance of the two - all measured as £ billion.

For every permutation of lives saved and GDP lost the costs of lockdown exceed the benefits. Even if lives saved are as high as 440,000, each of which means an extra 10 years of quality-adjusted life - and when the lost output (assumed to be a sufficient and comprehensive measure of all costs of the lockdown) is simply the likely shortfall in incomes in 2020 - costs are still over $50 \%$ higher than benefits of lockdown (benefits = $£ 132$ billion; costs $=£ 200$ billion). In all other cases costs are a multiple of benefits. In most cases, costs are 10 times or more the scale of benefits. This result reflects the fact that the economic costs of the lockdown - even on the most conservative estimate of $£ 200$ billion - is far larger than annual total expenditure on the UK national health service (which runs at around $£ 130$ billion); the benefits of that level of resources applied to health and using the NICE guidelines would be expected to generate far more lives saved than is plausibly attributable to the lockdown in the UK. 
Another way of making the same point is that the cost per QALY saved of the lockdown looks to be far in excess (generally by a factor of at least 3 and often by a factor of 10 and more) of that considered acceptable for health treatments in the UK.

$\begin{array}{ccccc}\text { Lives not } \\ \text { lost } \\ 440000 & 10 \% \text { GDP loss } & 15 \% \text { GDP loss } & 20 \% \text { GDP loss } & 25 \% \text { GDP loss } \\ & & & & \\ 200000 & -£ 134 \mathrm{~b},-£ 200 \mathrm{~b}, & £ 66 \mathrm{~b},-£ 330 \mathrm{~b}, & £ 66 \mathrm{~b},-£ 440 \mathrm{~b}, & £ 66 \mathrm{~b},-£ 550 \mathrm{~b}, \\ & £ 30 \mathrm{~b},-£ 200 \mathrm{~b}, & £ 30 \mathrm{~b},-£ 330 \mathrm{~b}, & £ 30 \mathrm{~b},-£ 440 \mathrm{~b}, & £ 30 \mathrm{~b},-£ 550 \mathrm{~b}, \\ 100000 & -£ 170 \mathrm{~b} & -£ 300 \mathrm{~b} & -£ 410 \mathrm{~b} & -£ 520 \mathrm{~b} \\ & £ 15 \mathrm{~b},-£ 200 \mathrm{~b}, & £ 15 \mathrm{~b},-£ 330 \mathrm{~b}, & £ 15 \mathrm{~b},-£ 440 \mathrm{~b}, & £ 15 \mathrm{~b},-£ 550 \mathrm{~b}, \\ 50000 & -£ 185 \mathrm{~b} & -£ 315 \mathrm{~b} & -£ 425 \mathrm{~b} & -£ 535 \mathrm{~b} \\ & £ 8 \mathrm{~b},-£ 200 \mathrm{~b}, & £ 8 \mathrm{~b},-£ 330 \mathrm{~b}, & £ 8 \mathrm{~b},-£ 440 \mathrm{~b}, & £ 8 \mathrm{~b},-£ 550 \mathrm{~b}, \\ 20000 & -£ 192 \mathrm{~b} & -£ 322 \mathrm{~b} & -£ 432 \mathrm{~b} & -£ 542 \mathrm{~b} \\ & £ 3 \mathrm{~b},-£ 200 \mathrm{~b}, & £ 3 \mathrm{~b},-£ 330 \mathrm{~b}, & £ 3 \mathrm{~b},-£ 440 \mathrm{~b}, & £ 3 \mathrm{~b},-£ 550 \mathrm{~b},\end{array}$

Table 2: Table 2: benefits (+), costs (-) and net benefits of March-June UK lockdown; converted to an index of $£$ billions. 5 QALY are assumed lost for each COVID-19 death. Each life saved is estimated to result in 5 more quality adjusted years of life. The NICE resource threshold of $£ 30,000$ is applied to each of these quality adjusted years. The money value of GDP losses are taken as a proportion of 2019 GDP of $£ 2.2$ trillion. All resulting figures are in $£$ billions.

Taken at face value the numbers in Tables 2 and 3 would suggest the lockdown was not an effective policy and that severe restrictions should be eased now because the economic costs have been so high relative to likely benefits. 


$\begin{array}{ccccc} & 9 \% \text { GDP loss } & 15 \% \text { GDP loss } & 20 \% \text { GDP loss } & 25 \% \text { GDP loss } \\ \text { Lives not } & \text { lost } \\ 440000 & & & & \\ & £ 132 \mathrm{~b},-£ 200 \mathrm{~b}, & £ 132 \mathrm{~b},-£ 330 \mathrm{~b}, & £ 132 \mathrm{~b},-£ 440 \mathrm{~b}, & £ 132 \mathrm{~b},-£ 550 \mathrm{~b}, \\ 200000 & -£ 68 \mathrm{~b} & -£ 198 \mathrm{~b} & -£ 308 \mathrm{~b} & -£ 418 \mathrm{~b} \\ & £ 60 \mathrm{~b},-£ 200 \mathrm{~b}, & £ 60 \mathrm{~b},-£ 330 \mathrm{~b}, & £ 60 \mathrm{~b},-£ 440 \mathrm{~b}, & £ 60 \mathrm{~b},-£ 550 \mathrm{~b}, \\ 100000 & -£ 140 \mathrm{~b} & -£ 270 \mathrm{~b} & -£ 380 \mathrm{~b} & -£ 490 \mathrm{~b} \\ & £ 30 \mathrm{~b},-£ 200 \mathrm{~b}, & £ 30 \mathrm{~b},-£ 330 \mathrm{~b}, & £ 30 \mathrm{~b},-£ 440 \mathrm{~b}, & £ 30 \mathrm{~b},-£ 550 \mathrm{~b}, \\ 50000 & -£ 170 \mathrm{~b} & -£ 300 \mathrm{~b} & -£ 410 \mathrm{~b} & -£ 520 \mathrm{~b} \\ & £ 15 \mathrm{~b},-£ 200 \mathrm{~b}, & £ 15 \mathrm{~b},-£ 330 \mathrm{~b}, & £ 15 \mathrm{~b},-£ 440 \mathrm{~b}, & £ 15 \mathrm{~b},-£ 550 \mathrm{~b}, \\ & -£ 185 \mathrm{~b} & -£ 315 \mathrm{~b} & -£ 425 \mathrm{~b} & -£ 535 \mathrm{~b}\end{array}$

Table 3: benefits $(+)$, costs (-) and net benefits of March-June UK lockdown; converted to an index of $£$ billions. 10 QALY are assumed lost for each COVID-19 death. Each life saved is estimated to resulted in 10 more quality adjusted years of life. The NICE resource threshold of $£ 30,000$ is applied to each of these quality adjusted years. The money value of GDP losses are taken as a proportion of 2019 GDP of $£ 2.2$ trillion

Might it be that the calculations massively understate the benefits of lockdown? That would be the case if the value of lives saved is dramatically too low; some would say that it is. Estimates used in the US for the statistical value of a life place it slightly above $\$ 10$ million $(29,30)$. For a newborn who might expect 80 good years of life the NICE $£ 30,000$ number would generate a life value of $£ 2.4$ million - just under a third of the value if a statistical life is worth $\$ 10$ million. Goldstein and Lee (2020) (31) note that US health economists use values of around \$125,000 per year of life (Institute for Clinical and Economic Review 2020). That is also a bit over three times the NICE figure.

However, the $£ 30,000$ figure per QALY is the figure used in evidence-based resource decisions within the UK health system. It is not an arbitrary number. It is not based on likely future earnings lost or the value of future consumption - calculations that are open to the moral objection that they reduce the value of human life to how much people would have spent on commodities.

Instead, the figure we use for the value of a QALY is a measure of what is considered the highest level of resources (i.e. what part of GDP) in the UK health system that should be used to generate extra qualityadjusted years of life - and it is saving of lives which is what the lockdown was for. In using this yardstick, we are treating decisions on how to face COVID-19 in the same way as decisions in the UK are made about resources to apply to the treatment of cancer, heart disease, dementia and diabetes. On that basis, it would seem as though the benefits of the lockdown were lower - perhaps far lower- than its costs. Yet even if one used valuation of a QALY three times as great the figures in Tables 2 and 3 (with benefits raised by a factor of 3) that would still generate costs of the lockdown in excess of benefits in nearly all the cases considered.

That judgement is, however, made with the benefit of hindsight: we now know more about the scale of the economic costs of the lockdown than was known in March, and also know about how deaths and new infections have evolved across Europe. The more interesting policy issue is what it is best to do now: how quickly should the lockdown be eased given what we know now? That issue we consider in the next section.

\section{Section 6: what policy to adopt now?}

We apply a similar cost-benefit methodology to consider policy options for the level of restrictions applied in the UK over the next 3 months (July-September 2020). The options we consider fall under two broad 
headings:

1. Carry on with only very limited easing of restrictions

2. Move quickly to minimal lockdown (easing restrictions rapidly and relying on existing tracking of the cases/deaths to help prevent re-emergence of the virus)

We consider the following scenarios for the consequences of each policy for the evolution of COVID-19 deaths:

1. Very limited easing of restrictions results in a continuing steady fall in the death rate over 13 weeks down to single figures per week at the end of three months. Each week deaths are assumed to be 0.7 $\mathrm{x}$ deaths of the previous week.

2. For the policy of rapid easing of restrictions we consider three possible scenarios:

1. Deaths continue to fall but at a significantly slower rate than with a slow and limited easing of lockdown; each week deaths are $0.9 \mathrm{x}$ deaths of the previous week

2. Deaths continue at the start-June level of 1,230 per week and do not fall further

3. Deaths steadily increase back up to levels seen at the height of the UK pandemic; each week they are $15 \%$ higher than the week before.

The assumed paths of deaths under the 4 scenarios are shown in Table 4 . In each case, we set the initial level of deaths in the week prior to each scenario at the last ONS recorded figure for UK deaths in the week to June $12^{\text {th }}$ (1230 deaths).

The implied cost of the extra deaths from the easing policies (under scenarios i, ii. and iii) are shown towards the bottom of the table. These are the projected excess deaths under each easing scenario relative to the policy of continuing with the lockdown multiplied by the lost QALY per death and valued at $£ 30,000$ per QALY. These numbers are in $£$ billion and should be set against the estimated benefits from easing the lockdown.

Our low-end estimate of the (narrowly defined) cost of the March to early June lockdown was 10\% of GDP - a figure of $£ 200$ billion. One might assume that a continuation of the lockdown over the next three months with only a very limited easing of restrictions generates a further cost of the same size. But the rapid easing of restrictions is unlikely to generate zero costs. Such costs may still be substantial, though likely far lower than a continuation of lockdown policies. A conservative estimate of the benefits of quickly easing the lockdown is that the $£ 200$ billion costs under lockdown might be half that size. This would generate a benefit from easing of $£ 100$ billion over three months to be set against any extra lives lost.

Based on that assumption under all scenarios the cost of easing restrictions is a small fraction of the benefits - the maximum cost of $£ 14$ billion should be set against an estimate of benefits of $£ 100$ billion. One would need to value QALYs at $£ 220,000$ - over 7 times the NICE guideline value of £30,000 to make a continuation of the lockdown warranted in the scenario of the greatest number of live years not lost with costs / QALY much higher for less live years saved. That runs counter to agreed UK policy on the economic viability of health interventions (20). 


\begin{tabular}{|c|c|c|c|c|}
\hline from $12 / 6 / 2020$ & $\begin{array}{c}\text { Continue } \\
\text { Lockdown } \\
(0.7)\end{array}$ & $\begin{array}{c}\text { Ease } \\
\text { Scenario I } \\
(0.9)\end{array}$ & $\begin{array}{c}\text { Ease } \\
\text { Scenario II } \\
(1)\end{array}$ & $\begin{array}{c}\text { Ease } \\
\text { Scenario III } \\
(1.15)\end{array}$ \\
\hline week 1 & 861 & 1107 & 1230 & 1415 \\
\hline week 2 & 603 & 996 & 1230 & 1627 \\
\hline week 3 & 422 & 896 & 1230 & 1871 \\
\hline week 4 & 295 & 806 & 1230 & 2152 \\
\hline week 5 & 207 & 725 & 1230 & 2475 \\
\hline week 6 & 145 & 653 & 1230 & 2846 \\
\hline week 7 & 102 & 588 & 1230 & 3273 \\
\hline week 8 & 71 & 529 & 1230 & 3764 \\
\hline week 9 & 50 & 476 & 1230 & 4329 \\
\hline week 10 & 35 & 428 & 1230 & 4978 \\
\hline week 11 & 25 & 385 & 1230 & 5725 \\
\hline week 12 & 18 & 347 & 1230 & 6584 \\
\hline week 13 & 13 & 312 & 1230 & 7572 \\
\hline Total Expected Deaths & 2847 & 8248 & 15990 & 48611 \\
\hline $\begin{array}{c}\text { Additional expected deaths compared to } \\
\text { Lockdown }\end{array}$ & & 5401 & 13143 & 45764 \\
\hline $\begin{array}{l}\text { Cost of Easing ( } £ \text { billions) - each add. } \\
\text { death }=5 \text { QALY valued at } £ 30000\end{array}$ & & 0.81 & 1.97 & 6.86 \\
\hline $\begin{array}{l}\text { Cost of Easing ( } £ \text { billions) - each add. } \\
\text { death }=10 \text { QALY valued at } £ 30000\end{array}$ & & 1.62 & 3.94 & 13.73 \\
\hline
\end{tabular}

Table 4: Deaths and costs of deaths under different unlocking scenarios. Deaths are assumed to evolve week by week from the level in the week ending 12 June (1230) by a factor $0.7 ; 0.9 ; 1.0 ; 1.15$ for the lockdown and scenarios i, ii and iii respectively.

Figure 5 presents the same information in a slightly different way, calculating the net costs of an extension of the lockdown relative to a policy of immediate easing. Even taking the best estimate of lives not lost, the benefits of lives not lost, relative to the easing of restrictions, the cost of continued lockdown for a further 3 months from mid-June 2020 is £86.3billion.

Conclusion - lockdown has been massively costly and benefits unlikely to have matched it.

We find that the costs of lockdown in the UK are so high relative to likely benefits that a continuation of severe restrictions is very unlikely to be warranted. There is a need to normalise how we view COVID-19 because its costs and risks are comparable to other health problems (such as cancer, heart problems, diabetes) where governments have made resource decisions for decades. Treating possible future COVID-19 deaths as if nothing else matters is going to lead to bad outcomes. Good decision making does not mean paying little attention to the collateral damage that comes from responding to a worst-case COVID-19 scenario.

The lockdown is a public health policy and we have valued its impact using the tools that guide health care decision in the UK public health system. On that basis, and taking a wide range of scenarios of costs and benefits of severe restrictions, we find the lockdown consistently generates costs that are greater - and often dramatically greater - than likely benefits.

Weighing up costs and benefits of maintaining general and severe restrictions is necessary. That is how decisions over a wide range of public policy issues are made - many directly concerning public health issues. While there are inevitable risks in easing restrictions there are very clear costs in not doing so - a policy of "let's wait until things are clearer" is not reliably prudent. A policy of not easing restrictions until the point 
at which there is virtually no chance of a resurgence in infection rates rising is not a policy in the interests of the population.

Movement away from blanket restrictions that bring large, lasting and widespread costs and towards measures targeted specifically at groups most at risk offers is now prudent. Such a policy should probably have been started before June 2020; by June 2020 it was urgently needed.

Acknowledgements: None

Ethics approval and consent to participate: The analysis used nationally available general practice-level data with no patient identifiable data. Therefore we felt that Ethics Permission was not required.

Consent for publication: All authors consent to the publication of this article

Conflict of interest: No author has any conflict of interest

Funding: No external funding was accessed to fund the work

Figure legends:

Figure1 : Number of Reported Cases (7 day rolling average) as a ratio to the national population x 1 million.

Source: Our World in Data COVID-19 Dataset. Our World in Data is collaborative efforts between researchers at the University of Oxford, who are the scientific editors of the website content, and the nonprofit organization Global Change Data Lab, who publishes and maintains the website and the data toolshttps://ourworldindata.org/coronavirusDownloaded 10/6/2020

Figure 2: Number of Deaths Reported associated with COVID-19 (7 day rolling average) as a ratio to the national population $\mathrm{x} 1$ million.

Source: Our World in Data COVID-19 Dataset. Downloaded 10/6/2020

Figure 3: Excess Deaths in weeks 8-21 of 2020.

Difference to average in the same week in the previous 3 years $(2017 / 2018 / 2019)$ and shown as \% of average. Source: The Human Mortality Database Department of Demography at the University of California, Max Planck Institute for Demographic Research, Center on the Economics and Development of Aging (CEDA) www.mortality.org. Downloaded 9/6/2020

Figure 4 : Date of Implementation and Relaxation of National responses in selected countries.

The series is the COVID-19 Government Response Stringency Index which is a composite measure based on nine response indicators including school closures, workplace closures, and travel bans, rescaled to a value from 0 to $100(100=$ strictest response). Source: Blavatnik School of Government, University of Oxford,https://www.bsg.ox.ac.uk/research/research-projects/coronavirus-government-response-tracker

Figure 5 : The net extra economic costs of the lockdown relative to the easing of restrictions are assumed to be $£ 100$ billion. To that is added the cost of lives lost under lockdown. The benefits of lives not lost, relative to the easing of restrictions, is then deducted from the lockdown costs to generate a net cost figure under the three scenarios. The easing scenarios are: i) deaths still decline but slower than in Lockdown, ii) deaths remain at start June 2020 levels iii) deaths increase again back up to April 2020 peak levels. The equivalent cost/QALY is calculated by dividing the Lockdown costs (£100 billion) by the net number of lives not lost in that scenario times the number of QALYs for each death.

\section{References:}

1. Ferguson et al (2020), "Impact of non-pharmaceutical interventions (NPIs) to reduce COVID- 19 mortality and healthcare demand", Imperial College COVID 19 Response team report, 16 March 2020.

2. Dion Bongaerts, Francesco Mazzola and Wolf Wagner (2020), "Closed for Business", CEPR Discussion Paper 14814, May 2020. 
3. José Lourenço, Robert Paton, Mahan Ghafari,Moritz Kraeme, Craig Thompson, Peter Simmonds, Paul Klenerman, Sunetra Gupta (2020), "Fundamental principles of epidemic spread highlight the immediate need for large-scale serological surveys to assess the stage of the SARS-CoV-2 epidemic ", medRxiv preprint doi: https://doi.org/10.1101/2020.03.24.20042291, March 2020.

4. Mike Stedman, Mark Davies, Mark Lunt, Arpana Verma, Simon G. Anderson and Adrian H Heald (2020), "A phased approach to unlocking during the COVID-19 pandemic - Lessons from trend analysis". Int J Clin Pract. 2020 May 7:e13528. doi: 10.1111/ijcp.13528.

5. Oscar Dimdore-Miles and David Miles (2020), "Assessing the Spread of the Novel Coronavirus In The Absence of Mass Testing", Covid Economics, issue 16, pages 161-176, May 2020.

6. T. Wieland (2020) "Flatten the Curve! Modelling SARS-CoV-2/COVID19 Growth in Germany on the County Level", pre-print available at https://www.medrxiv.org/content/10.1101/2020.05.14.20101667v2.

7. Karl J. Friston, Thomas Parr, Peter Zeidman, Adeel Razi, Guillaume Flandin, Jean Daunizeau, Oliver J. Hulme, Alexander J. Billig, Vladimir Litvak, Rosalyn J. Moran, Cathy J. Price and Christian Lambert (2020) "Dynamic Causal Modelling of COVID 19", Technical Report available at https://arxiv.org/ftp/arxiv/papers/2004/2004.04463.pdf.

8. Michael Levitt (2020) "The Corona Chronologies" available at: "https://www.dropbox.com/s/r4gxdvlcnrxet1i/1.The_Corona_Chronologies.\%20Part\%20I\%20\%20China.\%20Part\%20II.\%20Rest_of_World_Michael_Levitt\%2CStanford_r.pdf?dl=0.

9. Benjamin Born, Alexander M. Dietrich and Gernot J. Muller (2020), "Do lockdowns work? A counterfactual for Sweden", Covid Economics, issue 16, May 2020.

10. Dirk Krueger, Harald Uhlig and Taojun Xie (2020), "Macroeconomic dynamics and reallocation in an epidemic", Covid Economics, vol 5, April 2020.

11. https://www.ft.com/content/a26fbf7e-48f8-11ea-aeb3-955839e06441: accessed 12 June 2020

12. Pragyan Deb, Davide Furceri, Jonathan D. Ostry and Nour Tawk (2020), "The economic effects of Covid-19 containment measures". COVID Economics, CEPR, vol 24. May 2020.

13. Barthelemy Bonadio, Zhen Huo, Andrei A. Levchenko, Nitya Pandalai-Nayar (2020), "Global Supply Chains in the Pandemic", NBER Working Paper 27224, May 2020.

14. Sangmin Aum, Sang Yoon (Tim) Lee, Yongseok Shin (2020), "Doesn't Need Lockdowns to Destroy Jobs: The Effect of Local Outbreaks in Korea", CEPR Discussion Paper 14822.

15. Olivier Coibion, Yuriy Gorodnichenko and Michael Weber (a, 2020), "Labor markets during the Covid19 crisis: A preliminary view", COVID Economics, vol 21. May 2020, a.

16. Olivier Coibion, Yuriy Gorodnichenko and Michael Weber (b, 2020), "The cost of the COVID-19 crisis: Lockdowns, macroeconomic expectations, and consumer spending", Covid Economics, issue 20, May 2020 .

17. https://www.bankofengland.co.uk/-/media/boe/files/monetary-policy-report/2020/may/monetarypolicy-report-may-2020\#:accessed 11 June 2020.

18. http://www.pulsetoday.co.uk/clinical/clinical-specialties/respiratory-/gp-urgent-cancer-referralsdecline-by-more-than-70-as-fewer-patients-come-forward/20040662.article: accessed 11 June 2020.

19. https://www.england.nhs.uk/statistics/statistical-work-areas/hospital-activity/monthly-hospitalactivity/mar-data/: accessed 11 June 2020.

20. NICE (2013), "How NICE measures value for money in relation to public health interventions", Published: 1 September 2013 at: nice.org.uk/guidance/lgb10.

21. https://www.ons.gov.uk/peoplepopulationandcommunity/birthsdeathsandmarriages/lifeexpectancies/datasets/nationalli. accessed 10 June 2020.

22. Jonathan Valabhji, Naomi Holman, Peter Knighton, Partha Kar, Jackie O'Keefe, Matt Curley, Andy Weaver, Emma Barron, Chirag Bakhai, Kamlesh Khunti, Nick Wareham, Naveed Sattar, Bob Young (2020) "Type 1 and Type 2 diabetes and COVID-19 related mortality in England: a cohort study in people with diabetes", preprint available at https://www.england.nhs.uk/wpcontent/uploads/2020/05/Valabhji-COVID-19-and-Diabetes-Paper-2-Full-Manuscript.pdf.

23. https://digital.nhs.uk/data-and-information/publications/statistical/national-diabetes-audit/report-2- 
complications-and-mortality-2017-18: accessed 10 June 2020.

24. Clarke P, Gray A, Holman R. (2002) "Estimating utility values for health states of type 2 diabetic patients using the EQ-5D (UKPDS 62)". Med Decision Making. 22: pages 340-349

25. A Beaudet, J Clegg, P Thuresson, A Lloyd, P McEwan (2014) "Review of Utility Values for Economic Modeling in Type 2 Diabetes", Value in Health, Volume 17, Issue 4, June 2014, Pages 462-470

26. Arulampalam, W, P Gregg and M Gregory (2001), "Unemployment Scarring", The Economic Journal 111(475): F577-F584

27. Tumino, A (2015), "The scarring effect of unemployment from the early '90s to the Great Recession", Institute for Economic and Social Research Working Paper 2015

28. Carol Propper, George Stoye and Ben Zaranko (2020), "The wider impacts of the coronavirus pandemic on the NHS", IFS briefing (available at https://www.ifs.org.uk/publications/14798), April 2020.

29. E P Gentry, W K Viscusi. The fatality and morbidity components of the value of a statistical life. Journal of Health Economics, volume 46, p. $90-99$.

30. Kevin M. Murphy and Robert H. Topel. The Value of Health and Longevity. Journal of Political Economy 2006 114:5, 871-904.

31. Joshua R. Goldstein and Ronald D. Lee (2020), " Demographic Perspectives on Mortality of COVID-19 and other Pandemics", NBER Working Paper 27043.

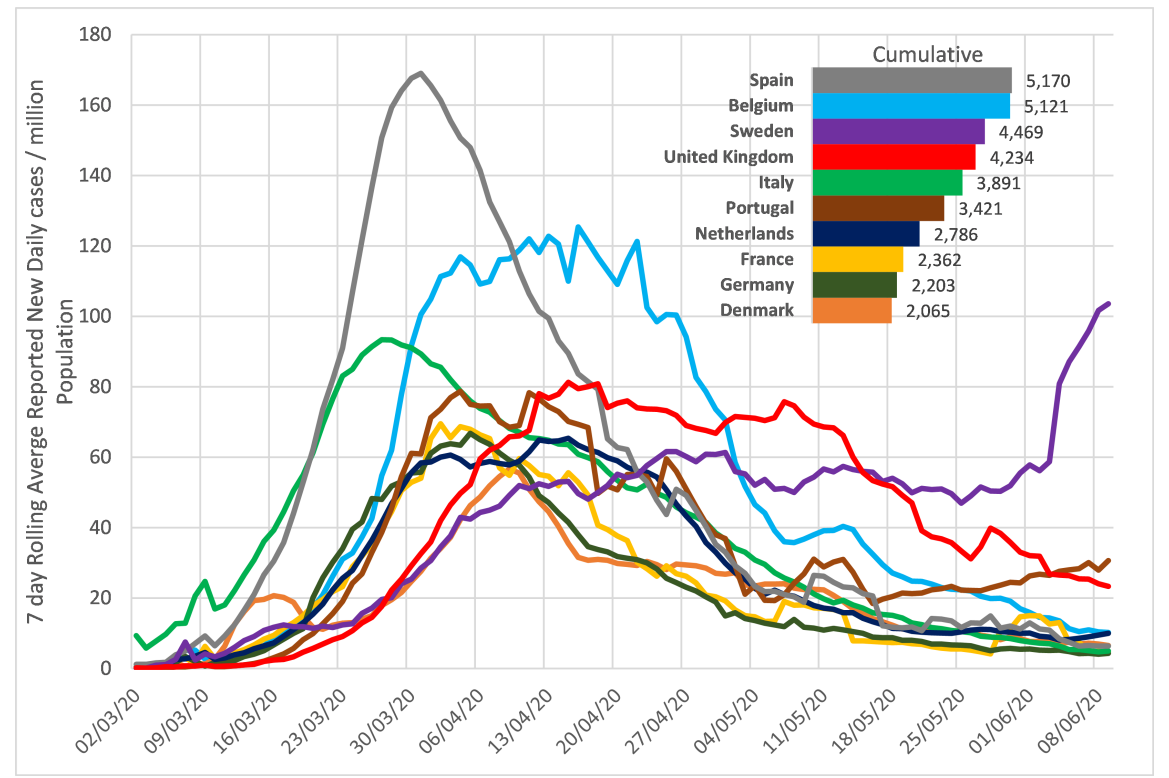



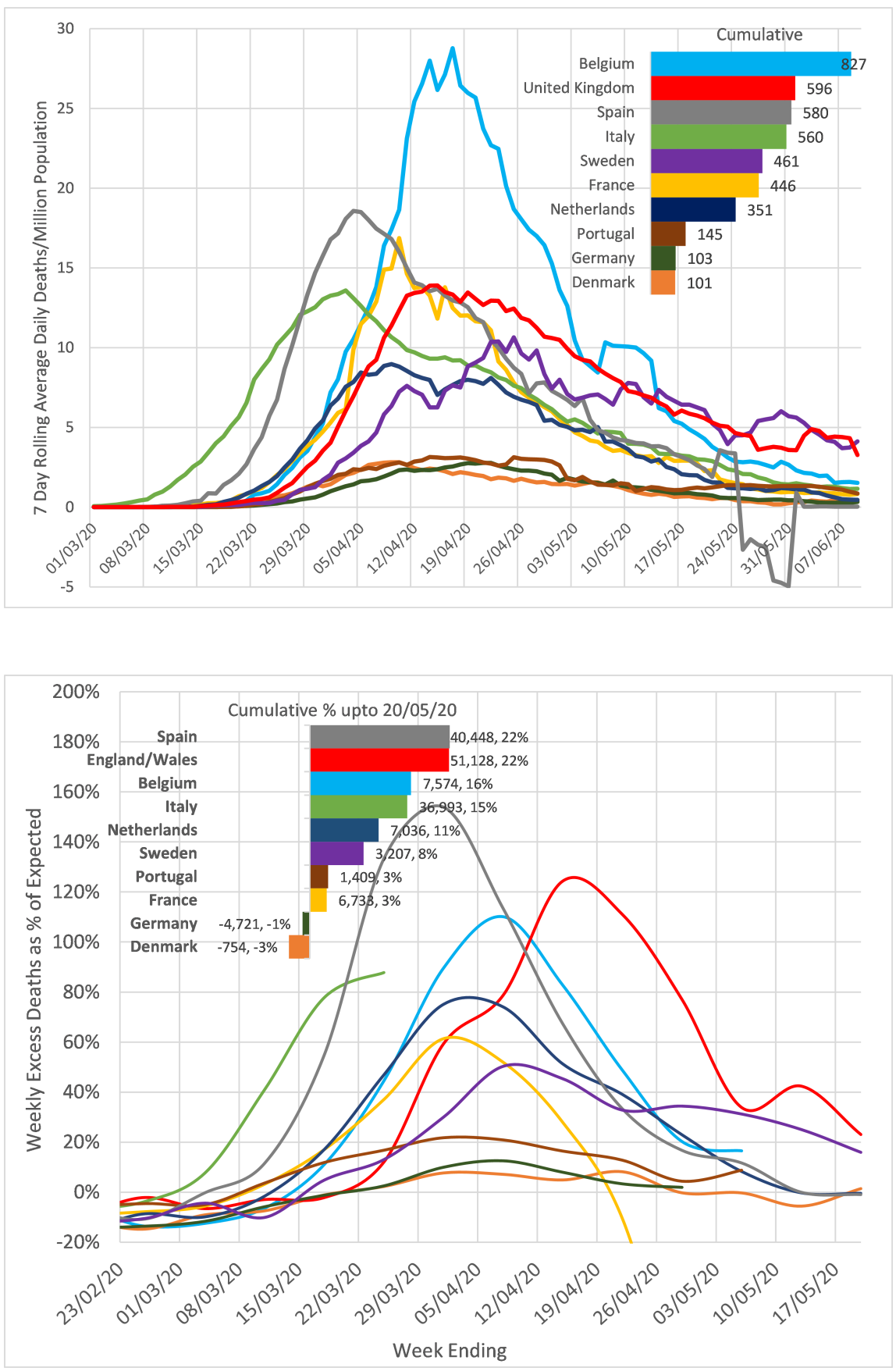


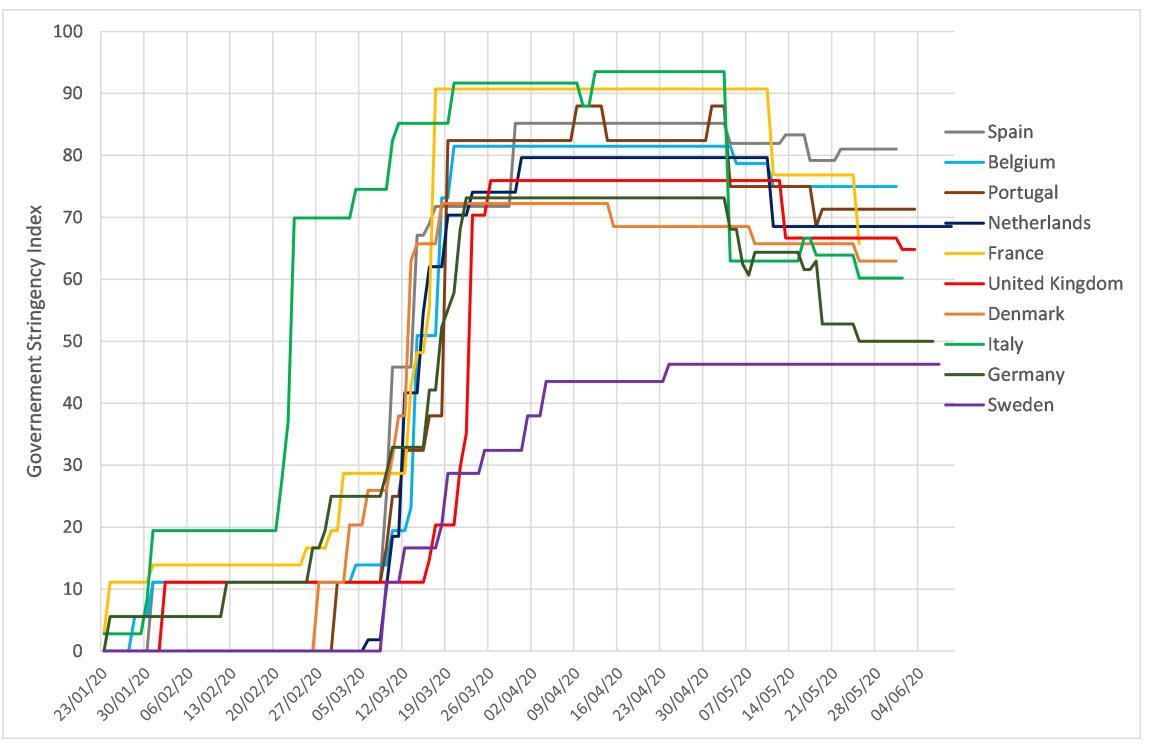

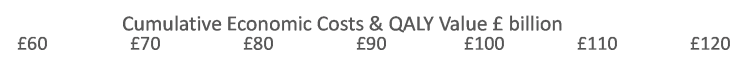
EACH FUTURE COVID-19 DEATH = 5 QALY @ £30,000/QALY Economic Impact of further 3months Lockdown QALY Value of Additional 2847 lives lost Scenario 1: QALY Value of 8248 lives not lost Scenario 2: QALY Value of 15990 lives not lost Scenario 3: QALY Value of 48611 lives not lost Lowest Lockdown Net Costs EACH FUTURE COVID-19 DEATH = 10 QALY @ £30,000/QALY Economic Impact of further 3months Lockdown

QALY Value of Additional 2847 lives lost

Scenario 1: QALY Value of 8248 lives not lost Scenario 2: QALY Value of 15990 lives not lost Scenario 3: QALY Value of 48611 lives not lost Lowest Lockdown Net Costs 